\title{
A INEFICÁCIA SOCIAL DA REABILITAÇÃO CRIMINAL
}

\author{
THE SOCIAL INEFFICACY OF CRIMINAL REHABILITATION
}

\author{
Cleidson Teixeira Vinhas ${ }^{1}$ \\ Vinícius Peter Schneider ${ }^{2}$ \\ Clóvis Dilli ${ }^{3}$ \\ Cristiano Telles Ginar ${ }^{4}$
}

RESUMO: O presente trabalho tem como objetivo analisar a evolução do Instituto da Reabilitação Criminal até os dias atuais, observando o contexto histórico deste instituto considerado por excelência, em países da Europa e América Latina. Seus pressupostos, aspectos humanos e sociais, e sua real eficácia na reinserção social do indivíduo egresso do sistema carcerário, bem como os que apenas foram submetidos a procedimentos de inquéritos policiais que restaram arquivados. Serão enfocados alguns casos práticos demonstrando a 952 divergência doutrinária e jurisprudencial, quanto à eficácia e utilidade deste instituto no Brasil. As consequências suportadas pelos indivíduos estigmatizados no contexto social, as violações da honra, imagem, privacidade, e presunção de inocência.

Palavras-chave: Reabilitação Criminal. Antecedentes Criminais. Estigmatização Social.

ABSTRACT: The present work aims to analyze the evolution of the Criminal Rehabilitation Institute up to the present day, observing the historical context of this institute considered par excellence, in countries in Europe and Latin America. Its assumptions, human and social

\footnotetext{
${ }^{1}$ Graduação em Administração de Empresa - Universidade Federal de Pelotas.

${ }^{2}$ Graduação em Direito - Universidade Federal de Santa Maria.

${ }^{3}$ Graduação em Tecnologia de Processos Gerenciais - Centro Universitário Uninter.

4 Graduação em Engenharia de Controle e Automação - Universidade Federal de Pelotas.
} 
aspects, and its real effectiveness in the social reintegration of the individual egressed from the prison system, as well as those that were only submitted to the procedures of police investigations that remained archived. Some practical cases will be focused, demonstrating the doctrinal and jurisprudential divergence, regarding the effectiveness and usefulness of this institute in Brazil. The consequences borne by individuals stigmatized in the social context, violations of honor, image, privacy, and presumption of innocence.

Keywords: Criminal rehabilitation. Criminal record. Social stigmatization.

\section{INTRODUÇÃO}

O presente artigo versa acerca da Reabilitação Criminal e os aspectos humanos de um instituto jurídico por excelência. Prevista no artigo 93 do Código Penal, a Reabilitação Criminal é o direito do condenado em obter, depois de cumprida ou julgada extinta por outra forma sua condenação, uma declaração judicial de que fora saldado o seu ônus com a sociedade, ou seja, um atestado de salvo conduto no qual consta que o indivíduo infrator está apto a viver e sociedade. Os efeitos decorrentes da sentença criminal, desaparecem gerando um sigilo referente aos antecedentes criminais de egresso do sistema prisional.

Para tanto, dever-se-á assegurar o sigilo dos registros da condenação e suspensos, condicionalmente, alguns de seus efeitos específicos. Para sua concessão, é imprescindível que o indivíduo apresente boa conduta nos dois anos que se seguiram ao cumprimento ou extinção da pena. Ademais, para que o retorno ao convívio social seja pleno, a Reabilitação Criminal deve permitir que o indivíduo fique livre do estigma condenador e, consequentemente, dos seus efeitos secundários que se materializam através dos antecedentes criminais, assim abolindo a mácula do ato criminal, pelo qual cumpriu uma sua pena, ou condenações extintas. 
Portanto, a Reabilitação Criminal encerra um ciclo que se inicia com o cometimento de um crime até a reintegração social do indivíduo. Sendo assim, constitui em ofertar um bônus ao apenado, eis que está vinculada ao bom comportamento.

\section{ORIGEM HISTÓRICA DA REABILITAÇÃO CRIMINAL}

\subsection{Conceito}

Originariamente, o termo reabilitação deriva do vocábulo latino "habilitare" e, no ponto de vista jurídico, tem como significado o exercício hábil para o retorno à atividades ou estado anterior.

Habilitar é tornar hábil, capaz, apto, credenciado, representa o devolver todas as qualidades e prerrogativas que o indivíduo um dia se viu privado, destituído em decorrência de fatos ocorridos anteriormente.

Em origem pátria, acrescentou-se o prefixo “RE”, que denota a formação do vocábulo reabilitação.

Reabilitar significa reintroduzir, reincorporar, retomar, devolver os direitos do indivíduo ao convívio social. Ademais, é definida como ciência de reintegração, e consequentemente inclusão social.

$\mathrm{Na}$ concepção do termo, reabilitar proclama o devolver a habilidade, aptidão, na concepção da palavra latina "habilis", significa que se pode carregar manejar, ser apto, capaz, conveniente.

No dicionário, o termo supramencionado é sinônimo de recapacitar, indicando a ação ou efeito de retornar ao estado físico, intelectual, moral, social, profissional, psicológico, e material que fora suprimido anteriormente. Ainda, traz o significado de recuperação da estima própria, por meio da regeneração ou recobro, do reconhecimento público por meio de uma qualidade ou sucesso, assim denotando o significado da palavra.

Reabilitar: v.t. I. Restituir ao estado anterior, aos primeiros direitos, prerrogativas, etc., ou à estima pública ou a particular. P.2. Readquirir a estima Pública ou particular, 
consideração pública: sua nova maneira de proceder reabilitou-o; Regenerar-se. / Conseguir reabilitação. §reabilitação sf. (FERREIRA, p. 462.)

\subsection{A Origem Histórica do Instituto}

A origem histórica do instituto da reabilitação criminal não é recente, assim como a maioria dos institutos do Direito pátrio, denota-se em várias culturas antigas o uso frequente da concessão da graça que nascia da benesse do príncipe, sendo comparada como ancestral da reabilitação. A origem da reabilitação remonta seu nascimento através de um sistema normativo rigoroso como era o do Direito Romano; suas raízes estão entrelaçadas na "restitutio in integrum", que se destinava à restituição, sendo entendida como benefício da restituição, e implicava no cancelamento integral dos efeitos da condenação, restituindo ao condenado todos os direitos e dignidades subtraídas pela sentença condenatória. Materializava-se em um privilégio concedido judicialmente, resultando na anulação de determinados atos lesivos praticados pelo beneficiário. A reabilitação era concedida principalmente aos condenados à deportação de Roma, assemelhando-se à concessão da graça no direito penal moderno, pois o

condenado tinha sua pena extinta, recuperava todos os seus bens, cancelava a nota de infâmia e resgatava o pátrio poder, conforme preleciona Prado (2007):

O instituto da reabilitação tem sua origem remota na restitutio in integrum, clemência soberana extintiva da pena e restauradora dos direitos - patrimoniais e morais - do condenado, utilizada pelos romanos no período da República e do império. (PRADO, 2007, p. 691).

O Direito Penal Romano instituía e utilizava o instituto jurídico da restitutio in integrum. Falconi (1995) defende que o benefício era pertinente e exclusivo do Direito Processual Civil, e que a partir da via pretoriana apartou-se definitivamente dos institutos declarados através da graça e indulgência. Em linhas atuais, o significado do termo seria o de restituição ao estado anterior, tratando-se de um privilégio concedido ao condenado, para que, judicialmente, seu postulante pudesse anular certos atos lesivos a determinados interesses.

Conforme Falconi (1995), a visão interpretativa do referido instituto, em um panorama geral, demonstrava ser o resultado de uma magnitude que poderia ser comparada a 
princípios e garantias na atualidade de ordem constitucional, visto que, após a formulação e conclusão do referido processo em época, as coisas retornavam ao seu estado anterior, como se o fato que originou a mutação sequer em algum momento tivesse existido, conforme preleciona o ilustre doutrinador:

Tratava-se de um remédio extraordinário à falta de outro remédio jurídico. A restitutio in integrum era concebida pelo magistrado, por via de decreto mesmo contra terceiros, anulando juridicamente o fato, como indicam suas expressões: 'RATUM NON HABEO PERINDE ERIT QUASE ID FACTUM NON SIT' (não tenho como ratificado, porém, como se não existisse o fato.)" (Silveira, Waldemar César Da, apud (FALCONI, 1995, p. 64)

Neste sentido, Falconi (1995) relata que nesta linha de pesquisa e entendimento no contexto da evolução do restitutio in integrum, denominado de benefício da restituição.

Outrossim, denota-se ser percebível, através do entendimento de Falconi (1995), que o referido instituto era de concepção moderna e inovadora para aquela época, o que em tempos atuais não se mostra condizente, dada a indiferença que recebe por parte dos operadores do direito. A restitutio in integrum, hoje Reabilitação Criminal, tinha como base de fundamento demonstrar que existia uma nova oportunidade para os bons cidadãos, se o indivíduo se demonstra, seriamente, que sua conduta compactuava com os padrões de exigência precedidos, para o regresso no convívio em sociedade.

A reabilitação criminal, em primórdios da idade média, esteve de certa forma, atribuída à graça e à indulgência consequência da benesse do príncipe, sendo que posteriormente foi constatado que estas não coadunavam com o objetivo do referido instituto.

A graça como era conhecida, e muito menos nos seus prefácios, não é considerada como direito subjetivo, mas sim um prêmio do Estado, que concedia quando, ao seu juízo ou critério, entendia ser necessário ou conveniente a seus interesses. Ao poder judiciário jamais seria concebida esta autonomia, pois ao juiz cabe analisar os fatos e aplicar o direito inerente ao caso, e não atender a supostos interesses políticos. Sintetizando, os interesses que 
norteavam o instituto da graça não eram técnico-jurídicos, mas sim meramente políticosubjetivos.

Podemos sintetizar a diferença entre graça e anistia da seguinte forma: esta declara a impunidade de certos indivíduos que tenham cometido algum delito, já aquela, diferentemente, reconhece a existência do crime, porém somente ataca a condenação, quer isentando-a, quer modificando-a. A diferença consiste, no fato de que a anistia é aplicável aos crimes políticos enquanto a graça aplica-se a crimes comuns.

\section{REABILITAÇÃO CRIMINAL NO ORDENAMENTO JURÍDICO PÁTRIO}

A Reabilitação Criminal no Brasil foi instituída através do advento do Código Penal de 1890 , sendo considerada como uma causa extintiva de condenação. Estava situada nos artigos 72, $\S 3^{\circ}$, e artigo 86 do referido diploma. Seu benefício era o de proporcionar ao réu a inocência após o trânsito em julgado da sentença de revisão criminal, e ele (réu), além de recuperar automaticamente todos os seus direitos, fazia jus a uma indenização por parte do estado advinda dos prejuízos causados pela condenação sofrida.

Posteriormente, tal instituto, porém de maneira diversa, restou consagrado em nosso atual Código Penal, de 1940, que elencou a Reabilitação Criminal em seu artigo ı08, VI, como sendo uma das causas extintivas de punibilidade, conforme segue:

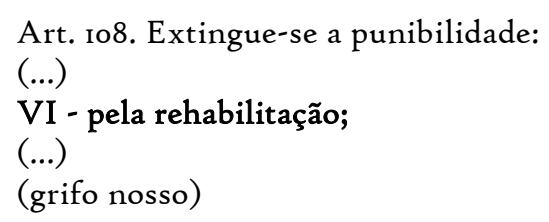

Em que pese a Reabilitação Criminal da época ser causa extintiva de punibilidade, seu alcance pratico se destinava unicamente às penas de interdição de direito, conforme segue:

Art. IIg. A reabilitação extingue a pena de interdição de direito, e somente pode ser concedida após o decurso de quatro anos, contados do dia em que termina a execução da pena principal ou da medida de segurança detentiva, desde que o condenado: (grifo nosso) 
Por sua vez, o Código de Processo Penal de 194I impôs um grande avanço em termos de garantia da intimidade do beneficiário do instituto para aquela época, conferindo autonomia própria à reabilitação, outorgando-lhe importante eficácia no quesito de vedar a publicidade da condenação anterior na folha de antecedentes e na certidão extraída dos livros do juízo do reabilitado, salvo quando fossem requisitadas por juiz criminal, conforme artigo 748 do referido diploma processual penal:

Artigo 748 - A condenação ou condenações anteriores não serão mencionadas na folha de antecedentes do reabilitado, nem em certidão extraída dos livros do juízo, salvo quando requisitadas por juiz criminal.

O referido artigo deu margem a requerimentos de reabilitação, cujo único objetivo era o de buscar o silêncio de condenações anteriores, embora quase sempre estivesse ausente a condenação à pena acessória de interdição de direito. Assim, aos poucos o âmbito da reabilitação foi sendo ampliado pelos Tribunais, culminando com a obtenção do silêncio sobre a condenação ou condenações anteriores de acordo com o previsto no Código de Processo Penal.

$\mathrm{Na}$ data de 5 de julho do ano de 1968, o instituto da reabilitação Criminal no Brasil passou a ter mais relevância e amplitude, pois com advento da Lei n. 5.467/68 seu alcance passou a submeter qualquer pena imposta em sentença definitiva, não estando mais atrelada a somente penas de interdição de direito. Houve, assim, evidente avanço do referido instituto e uma visível vontade de propiciar algo de mais positivo na tentativa de reinserção social do exapenado.

Art. II9. A reabilitação alcança quaisquer penas impostas por sentença definitiva. (Redação dada pela Lei no 5.467 , de 1968)

Segundo Falconi (1995), foram de grande monta as alterações implementadas no Código Penal pela referida lei, visto que o instituto mostrou-se mais condizente e engajado com o significado hermenêutico do próprio termo, conforme explana o renomado doutrinador. 
Com a nova redação do artigo II9, o instituto tomou foros de totalidade. Para que se possa aquilatar a mudança havida, vejam-se as redações de uma e outras normas. Quase tudo que não era permitido antes, passou a sê-lo a partir de antão. Abandonouse o critério restritivo de servir o instituto apenas para as penas acessórias, e, assim mesmo, umas poucas, para ampliar horizontes, visando alcançar também as penas principais, sem qualquer restrição quanto ao tipo legal ofendido. (Falconi, 1995, p. 97).

Atualmente, a Reabilitação Criminal não integra mais o contexto de causas extintivas de punibilidade, pois através da Lei n. 7.209/1984 foi instituído o Titulo V, Capítulo VII, do Código Penal, onde ganhou capítulo próprio, deixando de ser considerada como causa de extinção da punibilidade, mas tão somente suspendendo alguns efeitos penais da sentença condenatória. Passou, assim, a assumir maior relevância, abrangendo todas as penas e alguns efeitos da condenação. As penas acessórias foram extintas, as interdições de direitos passaram a ser tratadas como penas autônomas e foram inseridos os incisos I, II e III do artigo 92 do $\mathrm{CP}$, que trouxeram a perda do cargo, função pública ou mandato eletivo, a incapacidade para o exercício do pátrio poder, tutela e curatela e a inabilitação para dirigir veículo como efeitos da condenação. A reabilitação, atualmente, está prevista no artigo 93 do Código Penal, conforme segue:

\section{Reabilitação}

Art. 93 - A reabilitação alcança quaisquer penas aplicadas em sentença definitiva, assegurando ao condenado o sigilo dos registros sobre o seu processo e condenação.

Parágrafo único - A reabilitação poderá, também, atingir os efeitos da condenação, previstos no art. 92 deste Código, vedada reintegração na situação anterior, nos casos dos incisos I e II do mesmo artigo.

Cabe ressaltar, também, que foi inserida uma benéfica e significativa altercação no seu contexto, o que refletiu uma mudança drástica no quesito prazo do período de prova para postulação do benefício da Reabilitação Criminal, o qual, até então, era de quatro anos, como estipulado pelo Código de Processo Penal, tendo passado, através do advento da reforma do Código Penal pela Lei n. 7.209/1984, para dois anos, revogando subjetivamente o prazo anterior e diminuindo o período mínimo de prova, conforme segue: 
Código de Processo Penal:

\section{CAPÍTULO II \\ DA REABILITAÇÃO}

Art. 743.A reabilitação será requerida ao juiz da condenação, após o decurso de quatro ou oito anos, pelo menos, conforme se trate de condenado ou reincidente, contados do dia em que houver terminado a execução da pena principal ou da medida de segurança detentiva, devendo o requerente indicar as comarcas em que haja residido durante aquele tempo. (grifo nosso)

Código Penal:

\section{CAPÍTULO VII \\ DA REABILITAÇÃO \\ Reabilitação \\ Art. $93-(\ldots)$}

Art. 94 - A reabilitação poderá ser requerida, decorridos 2 (dois) anos do dia em que for extinta, de qualquer modo, a pena ou terminar sua execução, computando-se o período de prova da suspensão e o do livramento condicional, se não sobrevier revogação, desde que o condenado: (grifo nosso)

Segundo o artigo 94 do Código Penal, a reabilitação pode ser solicitada, quando decorridos dois anos do dia em que for extinta, de qualquer modo, a pena, ou terminar a sua execução, computando-se o período de prova da suspensão e o do livramento condicional, se não sobrevier revogação. Para tanto, é necessário que o apenado, durante o prazo de 02 anos após a extinção ou cumprimento da pena, tenha: a) tido domicílio no País durante esse período; b) tenha dado, durante esse tempo, demonstração efetiva e constante de bom comportamento público e privado; c) tenha ressarcido o dano causado pelo crime ou demonstre a absoluta impossibilidade de o fazer, até o dia do pedido, ou exiba documento que comprove a renúncia da vítima ou novação da dívida.

Esta evolução do conceito do instituto foi almejada como uma tentativa de política criminal de reinserção social do ex-condenado. Sua intenção, em parte, foi a de garantir o sigilo dos antecedentes criminais e suspender certos efeitos extrapenais da condenação, conforme se pode verificar pela exposição de motivos do Código Penal acerca de tal instituto, in verbis: 


\section{DA REABILITAÇÃO}

82. A reabilitação não é causa extintiva da punibilidade e, por isso, em vez de estar disciplinada naquele Título, como no Código vigente, ganhou Capítulo próprio, no Título V. Trata-se de instituto que não extingue, mas tão-somente suspende alguns efeitos penais da sentença condenatória, visto que a qualquer tempo, revogada a reabilitação, se restabelece o statu quo ante. Diferentemente, as causas extintivas da punibilidade operam efeitos irrevogáveis, fazendo cessar definitivamente a pretensão punitiva ou a executória.

83. Segundo o Projeto, a reabilitação não tem, apenas, o efeito de assegurar o sigilo dos registros sobre o processo e a condenação do reabilitado, mas consiste, também, em declaração judicial de que o condenado cumpriu a pena imposta ou esta foi extinta, e de que, durante 2 (dois) anos após o cumprimento ou extinção da pena, teve bom comportamento e ressarciu o dano causado, ou não o fez porque não podia fazê-lo. Tal declaração judicial reabilita o condenado, significando que ele está em plenas condições de voltar ao convívio da sociedade, sem nenhuma restrição ao exercício de seus direitos.

84. Reduziu-se o prazo de 2 (dois) anos, tempo mais do que razoável para a aferição da capacidade de adaptação do condenado às regras do convívio social. Nesse prazo, computa-se o período de prova de suspensão condicional e do livramento, se não sobrevier revogação.

85. A reabilitação distingue-se da revisão, porque esta, quando deferida, pode apagar definitivamente a condenação anterior, enquanto aquela não tem esse efeito. Se o reabilitado vier a cometer novo crime será considerado reincidente, ressalvado o disposto no art. 64. (grifo nosso)

Com a Lei no 7.209/84, a reabilitação teria assumido condição de maior dignidade no panorama dos direitos individuais e do interesse coletivo, permitindo o reingresso do condenado ao exercício de certos direitos dos quais fora privado em consequência direta ou indireta da sentença, conforme preleciona Falconi (1995):

É absolutamente imperioso que o Estado acredite na possiblidade real de o cidadão estar reabilitado, e deve, portanto, provê-lo dos meios necessários para essa difícil tarefa de se reintegrar numa sociedade, de regra, retrógrada e desconfiada, que prefere destacar sempre a parte negativa passada, à positiva que está por vir. (Falconi, 1995. p. 136).

Apesar da evolução histórica do instituto da Reabilitação Criminal no Brasil, estamos muito distantes da realidade aplicada e vivida em ordenamentos jurídicos de outros países, sendo que muitos destes foram espelhados de forma real e eficaz no berço do iluminismo 
francês. Mesmo com o considerável avanço trazido pela reforma de 1984, o instituto da reabilitação ainda não propicia o fim da estigmatização decorrente dos efeitos extrapenais da condenação e, consequentemente, não consegue impedir que se coloque uma marca negativa sobre a pessoa do condenado, estigma esta que se transforma em verdadeira pena intitulada de caráter perpétuo a ser suportada de maneira indelével pelo indivíduo.

\section{REINSERÇÃO SOCIAL}

$\mathrm{O}$ indivíduo ao ser encarcerado no sistema penitenciário, mergulha em um mundo a aparte, onde fica submetido ao exílio, que resulta na privação momentânea de sua própria identidade social.

A reinserção social do indivíduo egresso do sistema penal, é uma questão de problemática coletiva, visto que implica em uma posição de todos os envolvidos na sociedade, devendo ser repensada no quesito pré-conceitual. O condenado quando inicia o cumprimento da pena é isolado do contexto social, e a própria sociedade resolve seu problema momentaneamente, porém, o problema ira retornar quando este cumprir sua penalidade e

reingressar no seu antigo convívio, e ver-se privado das oportunidades em virtude da carga trazida pelo estigma, visto que o etiquetamento pós-pena, é em termos subjetivos visivelmente irreversível.

\section{CONCLUSÃO}

O presente artigo ateve-se em realizar um estudo sobre Instituto da Reabilitação Criminal no Brasil, especialmente no que se refere a sua capacidade de reintegrar o excondenado, e propiciar o efetivo sigilo dos registros da condenação. A reabilitação tal como se encontra em nosso ordenamento jurídico não é capaz de atingir a amplitude que a ela é reservada como medida de política criminal, pois mostra-se ineficaz em sua tentativa de buscar a reintegração do indivíduo e a recuperação de sua dignidade social, visto que a principal utilidade do instituto seria a de garantir o sigilo dos registros sobre o processo e a 
condenação do reabilitado. Nestas linhas cabe de maneira crucial deixar a mensagem do ilustre FRANCESCO CARNELUTTI:

Nem que aqui seja dito, ainda uma vez, contra a realidade que se quer de fato protestar. Basta conhecê-la. A conclusão de havê-la conhecido é esta: as pessoas creem que o processo penal termina com a condenação e não é verdade; as pessoas creem que a pena termina com a saída do cárcere, e não é verdade; as pessoas creem que o cárcere perpétuo seja a única pena perpétua; e não é verdade: A pena, se não mesmo sempre, nove vezes em dez não termina nunca. Quem em pecado está perdido. Cristo perdoa, mas os homens não. (FRANCESCO CARNELUTTI)

Conforme explanação do ilustre doutrinador, o fato de não ocorrer à efetiva eliminação dos antecedentes criminais, e estes resultando como perpétuos, faz com que o indivíduo, mesmo após ter sido declarado reabilitado, continue a carregar a marca negativa da condenação, esta sim, como uma verdadeiro estigma de caráter perpétuo. E como não deixar de lembrar a questão, dos inquéritos procedimentais arquivados que continuam a acautelar registros do indivíduo que foi investigado, estes demonstram somente uma única utilidade, qual seja, a desvalorização e desrespeito ao caráter humano, que estão materializados no estigma refletido pelos antecedentes de ordem perpétua.

É preciso ter coragem de estender a mão. A Reabilitação Criminal, sendo auferida por inteiro, sem limitações pré-conceituais seria o melhor caminho para todos, inclusive para os interesses maiores da sociedade, que é o de reduzir ao mínimo possível a incidência de criminalidade.

\section{REFERÊNCIAS}

BITTENCOURT, Cézar. Código Penal Comentado. São Paulo: Saraiva, 2004.

FALCONI, Romeu. Reabilitação Criminal / Romeu Falconi. - São Paulo: Ícone,1995. Elementos de Direito. 
FERREIRA, Aurélio Buarque de Holanda. Dicionário Aurélio Básico da Língua Portuguesa. Rio de Janeiro: Nova Fronteira, 2002.

MIRABETE, Julio Fabbrini. Manual de direito penal. 2o. ed. São Paulo: Atlas, 2003.

NUCCI, Guilherme de Souza. Manual de processo penal e execução penal. 5. ed. rev., atual. e ampl. 2. tir. - São Paulo: Editora Revista dos Tribunais, 2008.

PRADO, Luiz Regis. Curso de direito penal brasileiro, volume r: parte geral, arts. I.ㅇ a I20. 7 . ed. rev., atual. e ampl. - São Paulo: Editora Revista dos Tribunais, 2007 